\title{
O NÂO LUGAR COMO LUGAR DA EXPERIÊNCIA
}

\author{
Izilda Johanson ${ }^{1}$
}

Resumo: Um dos principais temas postos pela filosofia bergsoniana, no âmbito da subjetividade, é o da distinção entre consciência interior e exterior, entre uma interioridade, um eu interior, profundo, e uma exterioridade, um eu superficial, periférico. Ainda que o lugar seja, em princípio, algo pertinente apenas a um dos dois polos do eu - a saber, aquele relativo à exterioridade, à extensão e ao espaço -, a discussão acerca da natureza própria da interioridade reconfigura a ideia de lugar, no pensamento bergsoniano, pois, na medida em que é duração, também o eu interior se apresenta como uma região muito particular da experiência e da vida. A amplitude e os limites da existência, posta então como efetiva experiência do indivíduo em meio a esses dois lugares extremos, irredutíveis e de naturezas absolutamente distintas, e também, por isso mesmo, a relação entre temporalidade e intencionalidade, é o que pretendemos abordar neste ensaio.

Palavras-Chave: Interioridade. Lugar. Experiência. Subjetividade. Metafísica.

I.

Segundo Bergson, a filosofia que se aplica à duração não pode ser a mesma que busca discorrer, explicar ou mesmo elucidar a noção de duração, como se discorre, esclarece ou se explica um conceito. A duração não é simplesmente um conceito da filosofia bergsoniana, ou mesmo, para Bergson, um conceito da filosofia geral: em Bergson, falar sobre a duração, discorrer acerca da sua natureza, explicá-la conceitualmente, isto é, recorrendo exclusivamente aos recursos de uma linguagem, mesmo de uma linguagem estritamente filosófica, é, antes de tudo, tomar distância da sua realidade, é, na verdade, buscar a compreensão de alguma coisa que ela não é, ou, o que parece ainda mais grave, proceder no sentido inverso ao da compreensão do que ela seja realmente.

A intuição é o conhecimento mais adequado à realidade da duração. Assevera Bergson que a intuição é o conhecimento da duração que se faz em duração.

\footnotetext{
${ }^{1}$ Professora Adjunta de Filosofia Contemporânea do Departamento de Filosofia e do Programa de PósGraduação em Filosofia da Universidade Federal de São Paulo (UNIFESP) e autora de Arte e Intuição - a questão estética em Bergson (Editora Humanitas) e Bergson - pensamento e invençâao (Editora FAP-Unifesp). E-mail: i.johanson@unifesp.br
}

http://dx.doi.org/10.1590/S0101-31732017000200005 
Partindo dessa afirmação, alguns questionamentos nos poderiam ser prontamente dirigidos por alguém de fora da filosofia (ciência ou senso comum, por exemplo), ou por alguém que não tivesse intimidade suficiente com a filosofia bergsoniana. A primeira ideia que poderia vir à mente, quando se sustenta que "a intuição é o conhecimento da duração que se faz em duração" é a ideia de lugar. E a pergunta poderia ser, pois: onde estaria a duração? Onde a encontraríamos? Em segundo lugar, e em consequência desse primeiro passo, poderíamos supor que a existência da duraçáo se desse como a realidade de uma espécie de mundo à parte, como uma realidade à parte daquela propriamente humana, e que aguarda simplesmente ser descoberta para que se possa, finalmente, por meio da intuição, nela adentrar. E, em terceiro lugar, não sendo externa, mas interna a nós, poderia ser entáo a duração algo como um estado de espírito diferente, especial, uma realidade outra do espírito, um "não sei o quê" que talvez "atingíssemos", abandonando nosso estado mental habitual, inteligente e racional?

\section{II.}

A ideia de um lugar que não se reduz de modo estrito ao espaço é, como se sabe, a teoria que Bergson identifica em Aristóteles e à qual, não por acaso, dedica a sua tese complementar à tese principal de doutoramento, o Ensaio sobre os dados imediatos da consciência, defendida em 1889, na Sorbonne. A tese complementar de Bergson trata precisamente da teoria do lugar desenvolvida no livro IV da Physis de Aristóteles. Liga-se à tese principal por meio da interpretação, no mais desfavorável, que Bergson tece a respeito da teoria aristotélica, a qual, segundo ele, insere o espaço dentro do corpo e, com isso, decreta a sua inviabilidade. Cito Bergson (2013, p. 47):

Falando claro, o lugar é necessariamente aquilo em que e para o que o corpo se move. Um corpo não pode mover-se dentro de si, nem, por um movimento natural, buscar o alto e o baixo se, em si mesmo, tem essas diferenças. É preciso portanto que estabeleçamos fora do corpo não só essas diferenças, mas também o teatro do movimento.

Para além disso, segundo Bergson, ao recusar a concepção de um vazio - concepção, pode-se dizer, que mais se aproximaria do nosso espaço moderno - Aristóteles foi levado a conceber a teoria do lugar como a de 
um "espaço qualitativo", ou, como destaca Arnaud François, na edição crítica dos Écrits Philosophiques de Bergson, de uma "extensão percebida”, que é, justamente (acrescentamos por nossa conta), o que se poderia supor ser o objeto central do Ensaio sobre os dados imediatos da consciência, que recoloca a questáo da natureza do eu psicológico, um eu que, enquanto interior, se encontraria nas profundezas de si mesmo, num suposto lugar sensivel denominado "eu profundo". Mas é o próprio Arnaud François que esclarece o propósito que salta do cruzamento dessas duas teses bergsonianas, a principal e a complementar: "[...] para abordar corretamente a duração e sua distinção em relação ao espaço, tal como o Ensaio propóe, é importante ter purificado previamente o espaço de tudo o que este pudesse conter de qualidade, e essa é a tarefa de $O$ que Aristóteles pensou sobre o lugar, operar essa purificação." (BERGSON, 2011, p. 133-134).

Como se enfatiza desde as primeiras linhas de o Ensaio sobre os dados imediatos da consciência, a duração interna - aquela que não é outra senão a personalidade de um indivíduo particular, a duração de alguém -, cujo contato possível só se faz por meio da intuição, náo pode, portanto, estar em lugar algum, já que ela é precisamente o que caracteriza a natureza do tempo, não do espaço.

Este parece ser também o ponto central do que esclarece Freud, na abertura de $O$ mal-estar na civilização, quando visa a explicar a natureza do eu psíquico, o processo de formaçãa, de constituição do ego e, consequentemente, a sua distinção de algo externo a si, um mundo exterior, cuja natureza é absolutamente distinta da sua. Para além de todas as particularidades, diferenças e mesmo oposiçóes entre as teorias fundadoras da psicanálise e as da metafísica bergsoniana, é precisamente da distinção fundamental de duas realidades opostas e irredutíveis - a saber, a vida mental, psíquica interior, e sua outra dimensão, mais externa, e de ambas em relação ao mundo exterior - que trata Freud, não só, mas também nessa passagem desse seu livro.

$\mathrm{O}$ que distingue fundamentalmente uma realidade interna de outra externa, no que diz respeito ao eu, ou ao ego, segundo Freud, é o fato de que, em relação ao psíquico, na esfera da mente, como ele salienta, o novo, a novidade não apaga necessariamente o antigo, o acontecido. $\mathrm{O}$ mesmo não se pode dizer, contudo, quanto ao que se compreenderá aqui por mundo exterior, seja esse mundo exterior um lugar geográfico, topográfico, ou mesmo corporal. Ao retomarmos a história de Roma - e este é o exemplo que 
o próprio Freud nos dá -, aprendemos com os historiadores que essa cidade passou por diversas modificaçóes e, hoje, um visitante, mesmo munido da mais farta documentação e do mais preciso conhecimento topográfico acerca do passado romano, encontrará na Roma atual ruínas, vestígios da história desse lugar:

Seu sítio acha-se hoje tomado por ruínas, não pelas ruínas deles próprios, mas pelas restauraçóes posteriores, efetuados após incêndios ou outros tipos de destruição. Também se faz necessário observar que todos esses remanescentes da Roma antiga estão mesclados com a confusão de uma grande metrópole que se desenvolveu muito nos últimos séculos, a partir da Renascença. Sem dúvida, já não há nada que seja antigo, enterrado sob o solo ou sob os edifícios modernos. Este é o modo como se preserva o passado em sítios históricos como Roma. (FREUD, 2006, p. 78).

Em contrapartida, no que concerne à vida psíquica, tudo se passa de modo muito diverso. Estendendo ainda a imagem de uma Roma antiga, mas, agora, por um esforço de imaginaçáo, supondo-a uma entidade psíquica, o que se poderia encontrar seria então uma Roma com um passado, semelhantemente longo e abundante, no entanto, "[...] uma entidade onde nada do que outrora surgiu desapareceu e onde todas as fases anteriores de desenvolvimento continuam a existir, paralela à última." (FREUD, 2006, p. 79). E isso, fundamentalmente, esclarece Freud - e no sentido muito favorável ao que nos interessa destacar, neste trabalho, quanto a Bergson -, porque,

[...] se quisermos representar a sequência histórica em termos espaciais, só conseguiremos fazê-lo pela justaposiçáo no espaço: o mesmo espaço náo pode ter dois conteúdos diferentes. Neste sentido, nossa tentativa [de comparar a vida psíquica com um lugar espacial] parece ser um jogo ocioso. Ela conta apenas com uma justificativa. Mostra o quão longe estamos de dominar as características da vida mental através de sua representação em termos pictóricos. (FREUD, 2006, p. 79).

Entretanto, e se, ao invés de uma cidade, a analogia fosse feita em relação a outro tipo de exterioridade, outro tipo de topografia, não mais de uma matéria inerte, mas agora de uma matéria viva, mais precisamente um lugar orgânico, isto é, um corpo? Também nesse caso, assegura Freud, encontraríamos a mesma situação: 
[...] as primeiras fases do desenvolvimento [de um corpo] já nâo se acham em sentido algum preservadas; foram absorvidas pelas fases posteriores, às quais forneceram material [...] Permanece, assim, o fato de que só na mente é possível a preservação de todas as etapas anteriores, lado a lado com a forma final, e também o de que não estamos em condições de representar esses fenômenos em termos pictóricos [...] O que se passou na vida mental pode ser preservado, não sendo, necessariamente, destruído. [...] Podemos apenas prender-nos ao fato de ser antes regra, e não exceção, o passado achar-se preservado na vida mental. (FREUD, 2006, p. 80).

Segundo a visão psicanalítica, apesar da "aparência enganadora” dessa certeza que costumamos carregar conosco acerca do nosso sentimento do eu, de nossa consciência de nós mesmos, é acertada a consideração de que "[...] o ego seja continuado para dentro, sem qualquer delimitação nítida, por uma entidade mental inconsciente chamada de $i d$, à qual o ego serve como uma espécie de fachada." (FREUD, 2006, p. 76). Completa Freud, nesse sentido: a pesquisa psicanalítica deverá ter ainda muito mais a dizer a respeito da relaçáo entre o ego e o id, no entanto, há que se considerar que, "[...] no sentido do exterior, porém, o ego de qualquer modo, parece manter linhas de demarcação bem claras e nítidas." (FREUD, 2006, p. 75). Assim, é nessa relação entre a dimensão mais exterior e aquela mais interior do eu, entre o ego e o id, em termos mais propriamente freudianos, que a individualidade ou, mais precisamente, a distinção entre o subjetivo (psíquico) e o objetivo (exterioridade) vai se constituindo.

Já desde os primeiros escritos, a psicanálise nos ensina que esse processo é constituinte e não constituído, em termos de existência. Os estudos empreendidos por Freud demonstraram, desde seu início e ao longo de todo o seu desenvolvimento, que o sentimento de um ego adulto náo pode ser o mesmo desde o início de sua vida; no caso de uma criança recém- nascida, ela ainda não distingue seu ego do mundo externo como fonte de sensaçôes que fluem sobre ela. Nela, o processo de separação entre o eu e o mundo exterior começa a constituir-se no momento em que certas fontes de excitação - dentre as quais, a mais desejadas de todas, o seio da mãe - diferentemente daquelas que posteriormente serão identificadas como seu próprio corpo, parecem não ser satisfeitas, a não ser recorrendo a uma ação como, por exemplo, a de chorar. Desse modo, pela primeira vez, o ego é contrastado por um objeto, sob a forma de algo que existe exteriormente e que só é forçado a surgir por meio de uma ação especial. Dali por diante, prossegue Freud, 
[...] as fronteiras desse primitivo ego em busca de prazer não podem fugir de uma retificação através de uma experiência. [...] Assim, acaba-se por aprender um processo através do qual, por meio de uma direçáo deliberada das próprias atividades sensórias e de uma ação muscular apropriada se pode diferenciar entre o que é interno - ou seja, pertence ao ego - e o que é externo - ou seja, que emana do mundo exterior [...]. Desse modo, então, o ego se separa do mundo externo. $\mathrm{Ou}$, numa expressão mais correta, originalmente o ego inclui tudo; posteriormente separa, de si mesmo, um mundo externo. (FREUD, 2006, p. 76).

Para além da beleza das imagens e da conveniência da teoria freudianas sobre o ego e sua relação com o mundo externo, para a defesa da questão central deste trabalho, que visa não apenas a pontuar a diferença de natureza entre a vida psíquica - temporal, por princípio - e sua relação com o mundo exterior, ou seja, com tudo o que ocupa espaço ou um lugar, mas também, e principalmente, inserir essa distinção no contexto de uma dualidade ou polaridade realizada, antes de tudo, em meio a uma experiência, ou melhor, como experiência em meio à vida, o recurso ao texto freudiano visa, sobretudo, a abordar o tema da temporalidade a partir de um ponto de vista preciso. Tratar de interioridade, nesse sentido, tanto em Freud como em Bergson, e para além de suas diferenças contrastantes e inequívocas, é refletir sobre subjetividade, e uma subjetividade que, como tal, não pode ser imobilidade: o eu interior ou inconsciente, tenha ele as características ou a coloração que cada uma das respectivas teorias, psicanalítica e metafísica, lhe dão, em nada se assemelha a um lugar espacial - um mar, um oceano - onde se alojam impressóes externas convertidas em memória inerte. Com efeito, ainda que o inconsciente seja constituído e compreendido de modo muito diverso, em cada um desses pensadores, em ambos ele diz respeito a uma realidade que é temporal: fonte de uma personalidade individual e singular, a qual é, antes, movimento, ou movimentar-se em direção à luz da própria consciência.

Particularmente em relação à filosofia bergsoniana, essa interioridade característica da vida psíquica, mental, cuja natureza é opostamente diversa da exterioridade, constitui-se, pois, não em um conteúdo simplesmente, pelo menos não no sentido de algo que se encontraria "dentro de", ou no "interior de" algo exterior, como se num invólucro; de fato, justamente, esse interior, em Bergson, não é simplesmente conteúdo de uma personalidade e nem algo que tenha a ver com a espacialidade, não pode estar em, dado que náo ocupa nem pode ocupar um espaço. Por outro lado, essa interioridade desse eu se realiza, contudo, como 
um lugar, mas então num sentido inteiramente renovado: um lugar que diz respeito não mais ao espaço, a delimitaçóes espaciais, a fronteiras e divisões do espírito, porém, antes, à dualidade e, ao mesmo tempo, à unidade psíquica do eu, ou à consciência como movimento uno de um eu polarizado e intencional: de um lado, ocupado com a manutençáo da própria vida e a da espécie humana; de outro, a expressão de si próprio, isto é, liberdade de criação da própria vida e a vida humana, e ao próprio sentido de humanidade.

Uma vida mental, psíquica, profunda, a qual se realiza como criação de si, é a mesma que se pode dar a conhecer apenas em ato, como ato de consciência, movimento puro que necessariamente realiza algo, quer dizer, que se exterioriza e cuja exteriorização é, antes de tudo, expressão, expressão dessa realização. Em uma palavra, criação de um eu integral que surge em meio à tensão desses dois extremos da experiência, a da interioridade e a da exterioridade do eu, realizandose fundamentalmente como diferença de si, em meio à sua vida própria.

\section{III.}

No primeiro capítulo de Matéria e Memória, Bergson (2010) mostra que o corpo possui certa potência, a saber, a de selecionar imagens, de operar uma triagem e deixar na sombra tudo aquilo que não é útil, do ponto de vista da ação. Nos capítulos seguintes, aparecerá, todavia, uma questão deixada em suspenso e que corresponde a uma constatação muito simples: nós possuímos também outro tipo de potência, que é a capacidade ou potência de reconhecer imagens. Ora, o que está em questão aqui é justamente a memória. Seguindo com Alain Panero (2006), em sua análise sobre essa questão da consciência interna e externa, entendemos ser preciso considerar o que é sugerido no capítulo primeiro de Matéria e Memória, a propósito da percepção pura, a saber, que nós não escapamos a uma espécie de vir-a-ser automático: somos em boa medida "espíritos instantâneos", ou melhor, "instantaneizados", o que quer dizer, em outras palavras, que algo na seleção das imagens se faz a partir de nós, mas sem nós mesmos: um funcionamento quase maquinal, isto é, feito menos a partir da intervenção do espírito e muito mais em função de uma necessidade vital. ${ }^{2}$ Nele, as imagens passam e repassam por nós e em nós e produzem reaçóes e comportamentos, por sua vez, quase automáticos também, os quais supóem uma

\footnotetext{
${ }^{2}$ Nesse sentido, a vida biológica e, por extensão, social, é que escolheria por nós. Em contrapartida, se, como quer a filosofia bergsoniana, o espírito é sinônimo de consciência, em relação à vida individual e à vida como totalidade, a ação consciente significará sempre ação livre. Ser, consciência e memória, em Bergson, significam, pois, liberdade.
} 
forma de reconhecimento, entretanto, não de um reconhecimento consciente. Desse modo, destaca Panero, toda a questão metafísica, do real, do ser, do que é efetivamente, em Matéria e Memória, está posta nessa distância entre, de um lado, o reconhecimento automático, um reconhecimento que se faz pelo corpo, um reconhecimento impessoal que não é de ninguém, mas da ordem das necessidades vitais (como, de resto, já o indica o título do segundo capítulo, "do reconhecimento das imagens"), e, de outro, o reconhecimento plenamente consciente, que é um reconhecimento pelo eu: ou, o que significa o mesmo, o meu reconhecimento personalizado, o qual implica uma apropriação, uma interiorização, uma escolha, enfim, mas então feita no âmbito da singularidade, ou seja, da interioridade e do espírito, como, no mais, o indica o título do capítulo terceiro ("da sobrevivência das imagens: a memória e o espírito").

Tendo sido expostos os problemas centrais dos dois capítulos de Matéria e Memória, a questáo inevitável, e que Panero ressalta, é a seguinte: essa distância entre um reconhecimento automático e um reconhecimento intencional seria real ou ilusória? O reconhecimento, em todos os níveis, faz-se sempre sem a intervençáo do nosso eu, sempre às cegas, sempre maquinalmente, mesmo quando nós imaginamos escolher livremente? Sabemos que a resposta de Bergson aceitará a realidade desse reconhecimento intencional e rejeitará essa segunda hipótese de um determinismo cego abatendo-se sobre a nossa existência. As consequências disso colocam em destaque o espiritualismo de Matéria e Memória, em princípio, afirmado como um antimaterialismo, na medida em que Bergson sustenta que o passado não se conserva no cérebro, mas em si mesmo. Melhor dizendo, o passado se autoconserva e se distingue das potências e funcionalidades estritamente corporais, da memória e do reconhecimento feito pelo corpo. Ele também náo está no corpo, e nem em lugar algum, porque que é a própria unidade do eu, quer dizer, a consciência de um indivíduo em sua singularidade, em sua personalidade própria, de sorte que o espiritualismo bergsoniano, como enfatiza Panero, não é um eternitarismo:

Para Bergson, o que está sempre em jogo, o que é a verdadeira questão, é a continuação do espírito. Bergson mais busca o espírito do que o póe. Lembremos que sua intuição do espírito, da duração, não é uma intuição intelectual; não é nada como uma intuição fora do tempo de uma substancialidade eterna dada de uma vez por todas com todas as suas determinaçóes. Essa intuição bergsoniana é, antes, o esforço de uma busca de um absoluto movente que já não é mais aquilo que acreditamos ter apreendido dele quando o apreendemos. A intuiçáo da duraçáo é um ato, um esforço que deve ser incessantemente retomado. Não é uma tranquila constatação daquilo que, conosco ou sem nós, são o que sáo desde sempre. (PANERO, 2006, p. 35). 
Isso nos leva ao entendimento em conformidade com o comentador de que, quando Bergson se interessa pela arte, pela ação, pela invenção científica, pelo fato místico, como o faz, de fato, ao longo de toda a sua obra, de maneira mais ou menos direta, o que ele busca é sempre precisar esse dinamismo de uma participação na criação, precisar essa experiência de uma continuação da duração, o qual não é nunca um simples desenrolar automático, mas sempre uma atividade singular de um indivíduo particular voltado à subjetividade, direcionado para o polo criador da vida.

\section{IV.}

Mencionamos aqui questôes próprias de Matéria e Memória, porém, entendemos que seja possível encontrar os fundamentos dessa interioridade (que não é puro conteúdo de uma forma que pretensamente o contenha) já no primeiro livro de Bergson, o Ensaio sobre os dados imediatos da consciência - no qual, no mais, os termos interioridade, eu interior, eu profundo, são abundantemente empregados -, embora, nessa primeira obra, o eu constituído ao longo de suas análises seja um eu ainda desprovido de corpo, e suas relaçóes com ele ainda não estejam plenamente estabelecidas, o que ocorrerá, de fato, apenas em sua segunda obra.

Estará no segundo capítulo do Ensaio o fundamento que Bergson dará à distinção maior entre espaço e duração, entre exterior e interior, e aquilo que faz desta uma distinção rigorosa. Essa operação se faz em meio à análise da ideia de número, cujo propósito maior é não só marcar a participaçáo do espaço na constituição deste último, como mostrar que é nele que se encontra o seu fundamento exclusivo. É sob a luz da ideia de número, portanto, que Bergson procede à distinção de duas multiplicidades, uma de natureza quantitativa, formada a partir da numeração e sustentada no espaço, e outra que se apoia em uma estrutura diversa, a qual, de saída, se nos apresenta inteiramente oposta à primeira. Bergson nos póe, assim, diante do que se anuncia como pertencendo a duas ordens distintas de fenômenos, associados, e dois tipos particulares e distintos de experiência: os objetos materiais e a objetividade, de um lado, e os fatos de consciência e a subjetividade, de outro. Ao proceder à análise da ideia de número, algo relacionado a certo ponto de vista de nosso espírito sobre as coisas se revela, a saber: contar implica que nós nos representamos os objetos ao mesmo tempo como idênticos e distintos, isto é, que nós não os distinguimos senão pelo lugar que ocupam no espaço. É a projeção num fundo homogêneo 
e ideal, ou seja, a disposição no espaço, que permite que as unidades sejam alinhadas e ocupem posiçóes diversas simultaneamente. Para adicionar, é preciso antes conservar, ou para determinar um número, é preciso operar uma soma e, portanto, para chegar ao todo numérico, é preciso que representemos as múltiplas unidades que o compóem, o que não é possível sem que haja a conservação da unidade, esse elemento que se repete e se destaca de si ao mesmo tempo. Sem a permanência simultânea de todas as unidades não se chega à totalidade numérica, dado que a repetição, por si só, não tem condiçóes de promover a numeraçáo, de sorte que a adição pode parecer um processo exclusivamente temporal, no entanto, é o espaço essencialmente que a viabiliza, porque, como revela a análise bergsoniana, para constituir um número, é preciso fixar, ou seja, é preciso representar simultânea e distintamente uma multiplicidade de pontos nesse vazio que é o espaço homogêneo, nesse suporte no qual as representaçóes (de pontos, de partes, de unidades) vêm se sobrepor.

O número é, pois, em princípio, resultado de um ato do nosso espírito, um ato de síntese, para sermos mais precisos, e náo uma propriedade das coisas, o qual não resulta, no entanto, de um processo temporal de adição, como determina, por exemplo, a estética transcendental kantiana. Para Bergson, ao contrário de Kant, o número é justamente o momento espacial dessa operação temporal que é a adição. A sucessão temporal não é composta de instantes exteriores uns aos outros e semelhantes entre si. Isto é precisamente o que caracteriza o processo de justaposição, o qual exige, por sua vez que o tempo seja justamente suprimido. E se o que se vê na sucessão é, na verdade, a justaposição - como o vê Kant - é inevitável que nela não se possa desenvolver uma duração concreta, progressivamente mutante e contínua. $\mathrm{O}$ espaço pertence à ordem da realidade na qual a unidade essencial a todo ato de espírito se objetiva. $\mathrm{O}$ ato simples do pensamento se fixa e torna-se, por isso, apto a coincidir com outras unidades objetivas, ou seja, fixadas. Nesse caso, a multiplicidade deverá vir sempre do objeto, quer dizer, das unidades justapostas no espaço, enquanto a unidade deverá vir sempre do sujeito.

\section{V.}

Precisemos melhor agora os termos objetivo e subjetivo, a partir da exposição posta no segundo capítulo do Ensaio. Bergson afirma: «Chamamos subjetivo o que parece inteira e adequadamente conhecido, objetivo o que é conhecido de tal maneira que uma multidáo sempre crescente de impressóes 
novas poderia substituir a ideia que dele temos atualmente.» (BERGSON, 1988, p. 62).

Poderíamos tomar apressadamente essa fórmula e sermos levados a compreender o oposto do que nosso filósofo propóe. O que sua definição indica é que o conhecimento subjetivo é o que se apresenta (ao sujeito) como inteiro e definitivo, enquanto o objetivo, ao contrário, se apresentaria como aquele parcial e provisório, passível de, a qualquer momento, ser outro. Ora, di-se-ia, não seria o contrário o que acontece, não seria o conhecimento objetivo aquele adequado e definitivo, e o subjetivo, ao contrário, aquele suscetível de ser constantemente substituído por outro? Vejamos, pois, o Bergson compreende sobre isso.

Em primeiro lugar, destaquemos os termos inteiro e adequado associados ao que Bergson concebe como subjetividade. Eles remetem a um tipo preciso de experiência, por meio da qual o sujeito revela sua natureza própria, isto é, a sua conciência como um contínuo de estados manifestos em sua integralidade, um todo único, sem rupturas ou descontinuidades. Em Evolução Criadora, Bergson chamará esse inteiro e adequado de simples, e este será aquele que se irá se opor, por princípio, à complexidade de uma unidade, pensada a partir de composição de partes, de concatenaçóes, associações, combinações de partes extrapartes, de unidades destacadas umas das outras, ou seja, de objetos. E náo há necessidade de que a unidade seja, de fato, dividida em uma multiplicidade de partes exteriores umas às outras, para que seja tomada como objetiva e exterior: basta que o seja de direito e, mais que isso, que essas divisôes náo produzam mudanças de natureza do todo. "Esta percepção atual, e não somente virtual, de subdivisóes no indiviso é precisamente o que chamamos objetividade." (BERGSON, 1988, p. 63).

As unidades com as quais a aritmética forma números são unidades provisórias, suscetíveis de se fragmentarem indefinidamente, e cada uma delas constitui uma soma de quantidades fracionárias tão pequenas e táo numerosas quanto se queira imaginar [...] Se toda multiplicidade; implica a possibilidade de tratar um número qualquer como uma unidade provisória que se acrescenta a si mesma, inversamente, as unidades são, por sua vez, verdadeiros números, táo grandes quanto se queira, mas que se considera como provisoriamente indecomponíveis para compô-los entre si. Ora, justamente porque se admite a possibilidade de dividir a unidade em tantas partes quanto se queira é que esta é considerada como extensa. (BERGSON, 1988, p. 61). 
O eu superficial diz respeito, pois, a esse lugar da consciência em que há justaposição de estados que a inteligência e a linguagem separaram uns dos outros, como se fossem de direito destacáveis, numeráveis, como pontos dispostos num plano espacial homogêneo. Trata-se de um sujeito que tende a objetivar-se; ou, o que é o mesmo, de um eu voltado à impessoalidade dos estados de consciência, nos quais a divisão ou segmentação, possível ou real, em partes ou segmentos promove diferenças de grandeza não de qualidade.

No extremo oposto desse eu objetivável, encontra-se o eu interior, ou a unidade subjetiva integradora dos estados de consciência que se sucedem e se interpenetram no tempo; que se dividem e mudam, promovendo diferenças e mudanças de natureza. O todo, que é a integralidade do eu, muda de natureza ao se dividir, e porque muda de natureza, só pode ser consciência inteira e inteiramente realizada:

Um sentimento complexo conterá um número bem grande de elementos mais simples; mas, enquanto esses elementos náo se destacarem com uma nitidez perfeita, não se poderá dizer que eles estavam inteiramente realizados, e, desde que a consciência tenha deles uma percepção distinta, o estado psíquico que resulta de sua síntese terá, por isso mesmo, mudado. (BERGSON, 1988, p. 62).

Concordamos, assim, com Deleuze (1999), quando assinala que seria um grande erro acreditar que a duração seja simplesmente o indivisível, embora Bergson, por comodidade, se exprima frequentemente assim. $\mathrm{Na}$ verdade, a duração divide-se e não para de dividir-se: eis por que ela é uma multiplicidade:

Mas que não se divide sem mudar de natureza; muda de natureza, dividindo-se: eis por que ela é uma multiplicidade não numérica, a qual, a cada estágio da divisão, pode-se falar de indivisíveis. Há outro sem que haja vários; número somente em potência. Em outros termos, o subjetivo, ou a duração, é o virtual. Mais precisamente, é o virtual à medida que se atualiza, que está em vias de atualizar-se, inseparável do movimento de sua atualização, pois a atualização se faz por diferenciação, por linhas divergentes, e cria pelo seu movimento próprio outras tantas diferenças de natureza. (DELEUZE, 1999, p. 31-32).

Essa distinção de objetividade e subjetividade, no âmbito do Ensaio, remete fundamentalmente a outra, operada no indivíduo, entre o que este 
tem mais próprio e singular - sua personalidade - e, na outra ponta, o que ele tem de comum e comunicativo em relação aos outros indivíduos - sua sociabilidade. Tal distinção, em termos bergsonianos, leva ao estabelecimento não de uma possível fratura no âmbito da existência individual, mas, antes, de dois modos bastante distintos de inserção na experiência. Trata-se, portanto, de diferenciar, no âmbito da vida, e de uma vida humana, o que se realiza, de um lado, em meio à temporalidade, a um tempo real, que é duração, mudança em ato, subjetividade, e, de outro, em meio à espacialidade, à abstração, à repetição, à objetividade.

\section{VI.}

Podemos agora chegar às nossas considerações finais. Vimos que, em Bergson, interior e profundo podem ser sinônimos de passado, de memória, de virtual, enquanto superficial pode ser considerado sinônimo de atual. É o passado que se atualiza por meio de uma ação de síntese operada pela consciência e, desse modo, se objetifica: o eu se fixa, se espacializa e passa, enfim, a ocupar um lugar, que não pode ser, em hipótese nenhuma, interior, porque o movimento real só pode ser aquele que se realiza no tempo, e o tempo náo para, nem retrocede. $\mathrm{Na}$ concretude da experiência da consciência de si, é o passado que se dirige em direção ao presente, não o contrário. Assim, em relação à interioridade bergsoniana, não há como compreender ao pé da letra uma expressão do tipo "mergulho na interioridade", no mais tão reiteradamente repetida pelo próprio Bergson, em especial no seu primeiro livro; não há como a consciência do eu mergulhar em sua própria interioridade, como se mergulhasse num mar profundo em busca de suas paisagens recônditas e insuspeitadas. Do mesmo modo, não há como pensar a consciência como a consciência de um eu interior, pois o eu, mesmo interior, só é consciência de si, na medida em que se exterioriza, ou seja, na medida em que se atualiza, ainda que o passado, o vivido, esteja integralmente vivo e presente, tal e qual vivido e, nesse sentido, diga respeito a uma interioridade.

Atualizar o passado significa, pois, inventar o presente, da perspectiva do eu psicológico, do ego, da consciência de si, significa criar-se integralmente como e $u$, um eu que se reconfigura inteiramente a cada novidade acrescida à sua história. Trata-se, enfim, de um movimento que se realiza entre os dois polos, dois extremos da experiência - espacialidade ou objetividade, de um lado, e duração ou subjetividade, de outro -, um movimento que, como tal, só 
pode ser temporal, um deslocamento do eu no tempo, no seu próprio tempo, processo de atualização que, em maior ou menor grau - já que, quanto mais profundo é o impulso, tanto mais livre, isto é, mais criadora é ação - constitui, por si, um lugar da experiência, isto é, uma existência de si e no mundo.

JOHANSON, Izilda. The non-place as a place of experience. Trans/form/ação, Marília, v. 40, n. 2, p. 89-102, Abr./Jun., 2017.

ABstract: One of the main issues posed by Bergson's philosophy in the field of subjectivity is the distinction between inner and outer consciousness; between an interiority, an inner deep self, and an exteriority, a superficial peripheral self. Even though place is in principle something pertinent only to one of the two poles of the self - namely, that relating to exteriority, extension and space - the discussion about the nature of interiority reconfigures the idea of place in Bergson's thought. This is because insofar as it is duration, the inner self also presents itself as a very particular region of experience and life. In this essay we address the extent and the limits of existence, posited as an effective experience of the individual in the midst of these two extreme, irreducible, and absolutely distinct places. In the same context, we also address the relation between temporality and intentionality.

KeYwords: Interiority. Place. Experience. Subjectivity. Metaphysics.

\section{REFERÊNCIAS}

BERGSON, H. Ensaio sobre os dados imediatos da consciência. Tradução de João da Silva Gama. Lisboa: Ediçóes 70, 1988. . Essai sur les données immédiates de la conscience. Paris: PUF. 2007. (Le Choc Bergson). . Matière et memoire. Paris: PUF. 2010. (Le Choc Bergson). . Écrits Philosophiques. Paris: PUF. 2011. (Le Choc Bergson).

. O que Aristóteles pensou sobre o lugar. Traduçáo de Ana Lia de Almeida Prado. Campinas: Editora Unicamp, 2013.

DELEUZE, G. Bergsonismo. Tradução de Luiz B. L. Orlandi. São Paulo: Editora 34, 1999. FREUD, S. Mal-estar na civilização. Rio de Janeiro: Imago, 2006.

PANERO, A. Corps, cerveau e esprit chez Bergson. Paris: L'Harmattan, 2006.

Recebido em 12/11/2016

Aceito em 02/02/2017 